\title{
1 Perinatal Trauma with and without loss experiences
}

2

3

4

5

6

7

8

9

10

11

Word count : 3493

Accepted 15.3.16

12

A. Meltem Üstündağ Budak, Gillian Harris \& Jacqueline Blissett

Perinatal trauma with and without loss experiences

Journal of Reproductive and Infant Psychology, 34:4, 413-425, DOI:

10.1080/02646838.2016.1186266

13 
Objective: The present study explored differences in mental health between women who experienced a trauma which involved a loss of foetal or infant life compared to women whose trauma did not involve a loss (difficult childbirth). Method: The sample consisted of 144 women (Mean age $=31.13$ ) from the UK, US/Canada, Europe, Australia/ New Zealand, who had experienced either stillbirth, neonatal loss, ectopic pregnancy, or traumatic birth with a living infant in the last 4 years. Results: The trauma without loss group reported significantly higher mental health problems than the trauma with loss group $(\mathrm{F}(1,117)=4.807 \mathrm{p}=.03)$. This difference was observed in the subtypes of OCD, panic, PTSD and GAD but not for major depression, agoraphobia and social phobia. However, once previous mental health diagnoses were taken into account, differences between trauma groups in terms of mental health scores disappeared, with the exception of PTSD symptoms. Trauma groups also differed in terms of perceived emotional support from significant others. Conclusion: The findings illustrate the need for a change in the focus of support for women's birth experiences and highlighted previous mental health problems as a risk factor for mental health problems during the perinatal period.

Key words: Perinatal trauma, perinatal loss, difficult childbirth

\section{Introduction}

Prenatal/postnatal loss and difficult childbirth experiences, (for parsimony, called 'perinatal

traumas' in this study), have been identified as predictors of postnatal mental health (Soet, Brack, \& Dilorio, 2003). It has been reported that $15 \%$ to $25 \%$ of women who experience perinatal loss suffer from adjustment problems and may seek professional help for their mental health problems (Hughes, Turton, Hopper, \& Evans, 2002).

Most common perinatal traumas include miscarriage, stillbirth, ectopic pregnancy, neonatal death and difficult childbirth (Brockington, 1996). Unlike other perinatal traumas, miscarriage has not been recognised as a risk factor for perinatal mental health problems until recently. One earlier qualitative study showed that miscarriage signified a major life event that changed the way in which women viewed their lives in the present, and affected the way in which they 
planned for the future (Bansen \& Stevens, 1992). Later studies also associated miscarriage with anxiety symptoms (Cumming et al., 2007). A recent longitudinal study also emphasised the risks for persistent psychopathology, particularly for vulnerable women, one year post miscarriage (Lok, Yip, Lee, Sahota, \& Chung, 2010).

Women's experience of stillbirth has been a neglected area, but has started receiving more interest since the study carried out by Hughes and colleagues, which showed that PTSD symptoms were common during the next pregnancy following stillbirth at 1 year post partum (Hughes, Turton, \& Evans, 1999). Furthermore, in a consecutive study, Hughes and colleagues found that contact with the stillborn infant (seeing / holding) was associated with increased post-traumatic stress disorder (PTSD) and that next born infants were more likely to show disorganised attachment behaviour. The authors' findings, in a 7 year follow up study, also indicated significantly higher and enduring symptoms of PTSD following a stillbirth experience (Hughes et al., 2002).

Most studies class ectopic pregnancy as a prenatal loss, and examine the effect of such experiences within the prenatal loss construct (Beck \& Driscoll, 2006; Ney, Fung, Wickett, \& Beaman-Dodd, 1994). Similarly neonatal death has also been studied with other perinatal traumas e.g. stillbirth. Boyle et al., (1996) showed that mothers who experienced stillbirth, neonatal or sudden infant death syndrome (SIDS) remained more likely than controls to display high levels of both anxiety (14\%) and depression (7\%) more than 2 years after their loss (Boyle, Vance, Najman, \& Thearle, 1996).

Difficult/traumatic childbirth has also been associated with postpartum mental health problems, particularly anxiety disorders, and has been identified as an extremely traumatic stressor (Beck, 2004). It has been reported that $1 \%-2 \%$ of women develop post-traumatic stress disorder as a result of difficult childbirth (Ayers, Eagle, \& Waring, 2006; Bailham \& Joseph, 2003). Alcorn et al. in a prospective longitudinal study of the prevalence of PTSD 
following childbirth, found that PTSD can result from a traumatic birth experience after controlling for pre-childbirth PTSD, depression and anxiety symptoms (Alcorn, O'Donovan, Patrick, Creedy, \& Devilly, 2010). In addition, predisposing factors such as anxiety in late pregnancy along with other psychiatric symptoms in late pregnancy, critical life events and the experience of delivery was found to be an important predictor of PTSD symptoms (Zaers, Waschke, \& Ehlert, 2008). Since the recognition of individual vulnerability in response to adversity in DSM-IV (American Psychiatric Association, 2000), PTSD symptoms following a difficult childbirth have attracted lot of research interest and the current literature suggests a link between PTSD symptoms and traumatic / difficult childbirth (Ayers \& Pickering, 2001; Wijma, Söderquist, \& Wijma, 1997). However, no other study has examined difficult childbirth in relation to other anxiety symptoms in the postnatal period.

Although some women who experience loss or traumatic childbirth trauma adjust well to the loss or trauma, other women will continue to suffer (Badenhorst \& Hughes, 2007). Boyle et al., (Boyle et al., 1996) also suggested that although bereaved mothers reported higher rates of psychological distress, not all bereaved mothers suffered from mental health problems following a perinatal trauma. Their findings suggested that women who were psychologically distressed soon after the loss were likely to still be distressed 8 months later and likely to remain so subsequently.

It has been argued that perinatal trauma may act as a trigger, turning vulnerability for mental health problems into actual disorders. Côté-Arsenault et al. suggested that it is not the gestational timing of the perinatal loss (miscarriage, stillbirth or neonatal) but the personal meaning of each loss that is important for adjustment to loss (Côté-Arsenault, Bidlack, \& Humm, 2001). For example, it has been shown that women who experienced a perinatal loss may begin to question their ability to conceive and to be able to give birth to a living child 92 like any other woman (Nansel, Doyle, Frederick, \& Zhang, 2005), or they may suffer from 
anxiety symptoms following a difficult childbirth and blame themselves for failing to have a successful birth and not being able to bond with their living infant (Czarnocka \& Slade, 2000).

$$
\text { However, whilst PTSD and OCD in perinatal loss (Bailham \& Joseph, 2003; }
$$

McGuinness, Blissett, \& Jones, 2011) have received considerable research interest, there is less research into perinatal panic disorder (Rambelli et al., 2010), agoraphobia, social phobia (Murray, Cooper, Creswell, Schofield, \& Sack, 2007), and generalised anxiety disorder (GAD) (Lim et al., 2005).

Perinatal mental health complications coincide with the very crucial period where bonding to the infant takes place for the mother, and for the infant, attachment to his/her mother. The parenting behaviour of women with anxiety disorders features reduced emotional involvement, impaired communication, and the women are less responsive to their children (Field, Healy, Goldstein, \& Guthertz, 1990). It is possible that anxiety disorders and their symptoms could also have a detrimental effect on the early relationship between a woman and her baby. For example, mothers with OCD and panic disorder were observed to be less warm and promoting of psychological autonomy than control group mothers (Challacombe \& Salkovskis, 2009). Mothers with PTSD symptoms may have difficulties in breastfeeding and bonding with their baby (Reynolds, 1997). Also, parental behaviour low in warmth has been documented in families with anxiety disordered parents (DiBartolo \& Helt, 2007). Mothers may experience difficulty in bonding with their infant following a difficult childbirth due to their increased PTSD symptoms (Beck \& Watson, 2008) or if the traumatic birth is associated with the baby, mothers may have difficulties in their relationships with their infants (Ayers et al., 2006).

The degree or perception of social support a woman experiences during and after the trauma is an important predictor of outcome. Recently the 'importance of maternity staff and 
care pathways' and high risk populations including women who have preterm or stillborn infants has been identified as a research focus on PTSD following childbirth (McKenzieMcHarg et al., 2015).

Social support is conceptualised as a multidimensional construct (House \& Kahn, 1985).

122 There are four identified attributes which are, emotional, informational, tangible, and

123 appraisal support (Cohen \& Wills, 1985). Research confirms the importance of social support, particularly emotional support, for better adjustment following perinatal trauma (Cacciatore, Schnebly, \& Froen, 2009; Leon, 1986). For the perinatal period, for example, in a phenomenolological study following a perinatal loss, parents defined their emotional

127 support needs as physical presence; being listened to and being allowed to express their

128 feelings; acceptance of their feelings and being given sympathy by health professionals

129 (Kavanaugh, Trier, \& Korzec, 2004). Another study focused on emotional needs and perinatal loss highlighted the need for acknowledging and validating the feelings of parents

131 (Davis, Stewart, \& Harmon, 1988).

132 Even though studies have examined a range of perinatal trauma experiences in relation to

133 mental health problems, currently no study has yet examined the mental health outcomes of

134 perinatal trauma for those women who experience loss and those women who have a surviving infant. Furthermore, the perceived emotional support from significant others,

136 during and after perinatal trauma has not been compared between groups with and without

137 loss. It is reasonable to expect that survival of the infant may reduce the experience of mental

138 health symptoms in comparison to women who lost their infants before or after childbirth. It

139 may also be that the mother's perception of support from significant others moderates the

140 extent to which mental health symptoms are experienced.

141 In light of the above literature, the present study investigated whether trauma with or

142 without loss of the infant resulted in greater psychological distress, with particular focus on 
143 symptoms of anxiety disorders including panic, obsessive compulsive symptoms, post-

144 traumatic stress and generalised anxiety symptoms. It also examined the perceived emotional

145 support from a partner, close family members and health practitioners between trauma

146 groups.

\section{Method}

148 Sample

149 A total of 144 women $($ Mean age $=31.13$ ) from UK, US/Canada, Europe, Australia/ New

150 Zealand took part in this study. Women who experienced a single perinatal trauma within the

151 last 4 years were included in this study (miscarriage (52), neonatal death (4), stillbirth (17),

152 ectopic pregnancy (4) or difficult childbirth (77)). A total of 67 women who experienced a

153 single perinatal trauma with loss (miscarriage, neonatal death, stillbirth and ectopic

154 pregnancy) constituted the 'trauma with loss' group, while 77 women who experienced

155 difficult childbirth with a surviving healthy baby constituted the 'trauma without loss' group.

156 Procedure

157 Participants were provided with an information sheet about the study which fully explained

158 the content of the questionnaires and informed consent to participate in the study was

159 provided by all participants. Each participant completed a set of web-based questionnaires

160 and submitted their answers anonymously online. The study was advertised on social

161 websites and the websites of some national and international organisations (Birth Trauma

162 Association UK; Share US, Australia/New Zealand (Sands AU); Magic Mums). At the end

163 of the study, participants were presented with a debriefing form signposting them to sources

164 of support and information in case taking part in the study had distressed them in any way. 
168 The Psychiatric Diagnostic Screening Questionnaire (PDSQ) : The PDSQ (Zimmerman \&

169 Mattia, 2001) is a self-report scale designed to screen for the most common disorders in the

170 Diagnostic Statistical Manual of Mental Disorders (American Psychiatric Association, 2000).

171 The measure has good to excellent levels of internal consistency, test-retest reliability, and

172 discriminant, convergent, and concurrent validity (Zimmerman \& Mattia, 2001). In this

173 study, the bulimia, abuse/dependence, somatisation, hypochondriasis and psychosis subscales

174 were not used.

175 Edinburgh Postnatal Depression Scale (EPDS): The EPDS (Cox, Holden, \& Sagovsky,

176 1987) was used to measure depressed mood in the postnatal period. This scale consists of a

17710 item self-report scale to assess depression. It was developed and validated specifically for

178 postnatal use and is used worldwide.

179

180 Background/demographic questionnaire: Participants also provided details of their

181 reproductive history, perinatal trauma, demographics and past history of mental health

182 problems prior to their perinatal trauma.

183 Perinatal Experience and Support Questionnaire: This questionnaire was designed to collect

184 information on women's experience of perinatal trauma(s) and their perceived emotional

185 support from significant others (partner/ husband, family, and health practitioners). It

186 consisted of five separate sections for each trauma experience. It is comprised of questions

187 regarding the details of the trauma experiences (e.g. 'type of trauma', 'when was the

188 perinatal trauma experience') and questions regarding the participant's satisfaction with the emotional support received from significant others ('Please rate the emotional support that 
191 likert type scale ( $1=$ not at all satisfied, $5=$ extremely satisfied $)$.

192

193 This study was reviewed and approved by University of Birmingham Research Ethics

194 Committee (ERN_10-0698).

\section{Results}

196 A preliminary analysis revealed that there were no significant differences between the two

197 trauma groups in terms of relationship, education, ethnicity, job status and age. However, the

198 two groups differed in past mental health history. A higher rate of previous mental health

199 problems was observed in the trauma without loss group. The results are presented in Table

200 1. (A pairwise execution was used for the analysis thus the number of participants varied in analyses, as indicated in the tables).

202 Following to the preliminary analysis a series of one-way ANOVAs were conducted to

203 examine mean differences between trauma groups in the PDSQ total and PDSQ subscales.

204 The findings are presented in Table 2 and Figure 1. There was a statistically significant

205 difference in women's PDSQ total scores between the trauma groups. The trauma without

206 loss group reported more psychological distress than the women who experienced trauma

207 with loss. Despite reaching statistical significance, the actual difference in mean scores

208 between the groups was small.

209 PDSQ sub-scores and EPDS by trauma groups

210 Similarly, this difference in psychopathology remained in symptoms of OCD, Panic, PTSD

211 and GAD. Homogeneity of variance assumptions was only violated for the trauma group's

212 OCD scores. However the trauma group's OCD scores were significantly different at a

213 stringent significance level $(\mathrm{p}=.01)$. The differences between groups in Major Depression, 
214 Agoraphobia and Social Phobia were not statistically significant. Furthermore there was no

215 statistically significant difference for the EPDS scores between groups (see Table 2 and

216 Figure 1).

217 Current mental health symptoms of trauma groups by previous mental health problems

218 It was noted that the groups differed in terms of previous mental health problems. In order to

219 understand whether the differences in the mental health scores for the trauma with and

220 without loss groups comes from higher pre-existing problems in these women, the above

221 ANOVA analysis was re-run examining only the mental health scores of the women $(n=107)$

222 in each group who did not report any previous mental health problems prior to their trauma

223 experience (Table 3).

224 As presented in Table 3 none of the general and specific mental health scores other than

225 PTSD scores differed between trauma with loss and without loss groups. Women with no

226 prior history of mental health problems, but who experience a perinatal trauma, are more

227 likely to report higher PTSD symptoms if their trauma involves a surviving infant than a loss.

228 Perceived emotional support by trauma groups

229 A series of one-way ANOVAs were conducted to examine mean differences between trauma

230 groups in perceived emotional support from significant others. The findings revealed a

231 significant difference in perceived emotional support from Health Practitioners and Partner

232 between the two trauma groups. For the trauma with loss group, perceived emotional

233 support from Health Practitioners and Partner was significantly higher than perceptions of

234 support reported by those without loss (Table 4).

\section{Discussion}

236 This study aimed firstly to explore differences in mental health scores between women who

237 experienced perinatal trauma with and without loss. Contrary to the expectations, analysis 
revealed that the trauma without loss group reported significantly higher mental health problems than the trauma with loss group. This difference remained in the anxiety specific mental health problems OCD, Panic disorder, PTSD and GAD but not in major depression, agoraphobia or social phobia. It appears that women who experienced a perinatal trauma

242 without an infant loss, suffered from more anxiety symptoms than women who experienced

243 an infant loss. However, once the previous mental health history was taken into account, this

244 difference disappeared for the general and specific mental health scores. However, there remained a significant difference in PTSD scores, with women who experienced trauma without loss reporting greater PTSD symptomology. This finding supports other literature

247 suggesting a link between increased PTSD and difficult childbirth (trauma without loss)

248 (Ayers \& Pickering, 2001; Ayers, Joseph, McKenzie-McHarg, Slade \& Wijma, 2008).

249 The women who experienced perinatal loss appeared to have fewer mental health problems in comparison to the trauma group with a living infant; however, they still suffered from general and specific mental health problems (Figure 1). It would therefore be inaccurate to conclude that women who experienced perinatal trauma without an infant loss are 'worse off' than the women who experienced perinatal trauma with loss. This study actually underlines the importance of understanding the trauma and individual vulnerabilities in relation to perinatal mental health. It appears that although women survive the perinatal trauma with a living infant, their view of their trauma experience appears to count more than the outcome of the trauma - a living infant vs. a deceased infant.

258 Findings from this study also suggested a significant difference between the trauma groups'

259 perceived emotional support. It appears that mothers who experience a trauma without loss 260 perceive less emotional support from their partners and health practitioners. In other studies mothers reported a lack of validation for their experiences (Ustundag - Budak, Larkin, Harris 
$262 \&$ Blissett, 2015) particularly from health care staff (Beck, 2011) as the outcome of the birth

263 was a live birth and the mothers perhaps felt that their experiences as whole were not

264 acknowledged. Social support, particularly emotional support from health care providers, has

265 been identified as an important factor for better adjustment following perinatal traumas

266 (Cacciatore et al., 2009; Iles \& Pote, 2015). In addition, Beck, in a recent metaethnography

267 analysis of traumatic childbirth, discussed the multiple, recurring, reinforcing, intensifying

268 causal loops, encompassing feedback behaviour and how such loops, in a domino effect,

269 influence the mothers' experiences after trauma. Beck stressed the importance of feedback in

270 order to tackle the reinforcing causal loops (Beck, 2011).The findings of the current study

271 thus highlight the importance of validation of mothers' experiences and the need for

272 compassionate care (Cornwell \& Goodrich, 2009) for women who suffered perinatal trauma

273 without loss. Health care staff and partners may show more compassion towards women who

274 experienced a perinatal trauma with loss (e.g. stillbirth or neonatal death) in comparison with

275 women who survived the trauma with a living infant because their focus is on the outcome of

276 the experience. It is plausible to speculate that this invalidation of experiences and feelings

277 could be detrimental to mental health, particularly in symptoms of PTSD. It has been argued

278 that validation, including empathy and accurate reflection of individuals' experiences, is

279 quintessential to both healthy development and treatment of psychological problems (Rogers,

280 1951). This may require further research in terms of perinatal trauma and also may have

281 implications for therapeutic interventions and their need to focus on the validation of

282 experiences. A current review of post-traumatic stress disorder following childbirth

283 (McKenzie-McHarg et al., 2015) highlights current issues around the failure of diagnoses of

284 PTSD symptoms where there has not been tangible trauma, for example a third-degree tear or

285 internal bleeding. The review also underlines the importance of acknowledging sub-threshold

286 symptomology. Women may suffer from a variety of symptoms of PTSD but not meet the 
287 criteria for PTSD diagnoses. Women are also less likely to receive emotional support and

288 validation from health care professionals where their trauma experiences are not

289 acknowledged. It is possible that the participants of this study may have perceived the lack of

290 emotional support due to their unrecognised trauma experiences.

291 Parallel with previous literature, the findings of the present study may suggest that previous

292 vulnerability to mental health problems is an important risk factor for poorer mental health

293 scores following a perinatal trauma experience (Milgrom et al., 2008). Pre-pregnancy

294 mental health history has been identified as a risk factor particularly for PTSD symptoms

295 following difficult childbirth (Ayers et al., 2009; Wijma et al., 1997; Zaers et al., 2008).

296 However, the findings also indicated a remaining significant difference between the PTSD

297 scores of the trauma groups with and without loss, who did not have previous mental health

298 problems. This suggests that women who experienced difficult childbirth maybe at risk for

299 PTSD even in the absence of vulnerability caused by previous mental health problems and

300 that this effect may be stronger in those women who have a living infant.

301 The subjective experience of adverse experiences underlines the importance of individual

302 variability in response to a trauma experience. Beck drew attention to the fact that what a

303 mother perceives as birth trauma may be seen quite differently through the eyes of health

304 professionals, who may focus on the live birth following traumatic birth experience (Beck,

305 2004). It has been recently highlighted that the experience of difficult childbirth, suggests a

306 near death experience for both mother and child, unlike other trauma experiences (McKenzie-

307 McHarg et al., 2015). It is plausible that when women experienced a threat to the survival of

308 themselves and/or their infant, their infant then may be a constant reminder of their trauma

309 experience while they struggle to adjust (Ayers et al., 2006). They may also be dealing with

310 difficulties in bonding and negative feelings such as failing to love or look after their infant 
311 well enough (Czarnocka \& Slade, 2000; Elmir, Schmied, Wilkes, \& Jackson, 2010). These

312 may contribute to the worsening mental health symptoms in this group.

313 This study has shown that mental health problems may be experienced by women who have

314 experienced both a live birth after a traumatic event as well as mothers who have experienced

315 an infant death. Mental health problems are more likely to be observed in those mothers who

316 had a previous history of mental health problems, but post-traumatic stress responses may

317 well be observed where there has been no such previous history. Examining and

318 understanding the influence of such factors is important in order to support women

319 accordingly.

\section{Limitations}

321 A possible improvement for this study would have been to record the time that had passed since the traumatic event. In this way, we could have examined the time since the trauma in relation to experience of mental health symptoms. However, mothers were only eligible for

324 the study if they had experienced their trauma within a 4 year period and so all traumatic and 325 loss experiences were relatively recent events.

Implications and Further Research

327 This study has implications for current provision of perinatal support. The findings

328 emphasise the need for emotional support for mothers who have experienced a difficult

329 childbirth with a living infant. In addition, there is an emerging need for a shift from

330 outcome based focus (the survival of infant), to an individual based focus for women's birth

331 experiences. In particular, the awareness of health professionals involved in childbirth and

332 the perinatal period, about how such traumas may have an effect on the mothers, regardless

333 of their healthy infant's survival, may improve the care provided to women who experienced

334 a traumatic birth. Psychological support may also be necessary for those women with 
335 previous mental health problems who experienced perinatal trauma. Health practitioners

336 should be informed of the emotional support needs of mothers who experience perinatal

337 trauma and there is a need for a greater awareness of the potential impact of trauma without

338 loss on later adjustment. Specific training for health practitioners about how to validate

339 women's experiences should be considered. Similarly, the need for support after traumatic

340 perinatal trauma could also be disseminated to women's partners. These findings call for a

341 significant shift of emphasis in the prioritisation of care to include support for women who

342 have experienced difficult births as well as mothers who have suffered a pregnancy loss.

343 The research implications of this study are twofold. Firstly, it is very important to understand

344 the underlying factors that influence the women's view of their own trauma experiences in

345 order to support women perinatally. Further research is needed to understand the factors

346 which may influence women's view of their traumatic experiences and perceived social

347 support. Secondly, there is a need to investigate whether health professionals may behave

348 more sympathetically towards women who have given birth to a deceased infant and yet

349 failed to validate experiences of women who had a difficult childbirth with a living infant.

350 These hypotheses require further research.

\section{Acknowledgements}

352 The authors would like to thank all the women who participated in this study.

\section{References}

354 Alcorn, K. L., O’Donovan, A., Patrick, J. C., Creedy, D., \& Devilly, G. J. (2010). A

355 prospective longitudinal study of the prevalence of post-traumatic stress disorder

356 resulting from childbirth events. Psychological Medicine, 40, 1849-1859.

$357 \quad$ doi:10.1017/S0033291709992224 
American Psychiatric Association. (2000). DSM-IV. Diagnostic and Statistical Manual of Mental Disorders 4th edition TR.

Ayers, S., Eagle, A., \& Waring, H. (2006). The effects of childbirth-related post-traumatic stress disorder on women and their relationships: a qualitative study. Psychology, Health \& Medicine, 11, 389-398. doi:10.1080/13548500600708409

Ayers, S., Harris, R., Sawyer, A., Parfitt, Y., \& Ford, E. (2009). Posttraumatic stress disorder after childbirth: Analysis of symptom presentation and sampling. Journal of Affective Disorders, 119, 200-204. doi:10.1016/j.jad.2009.02.029

Ayers, S., Joseph, S., McKenzie-McHarg, K., Slade, P., \& Wijma, K. (2008). Post-traumatic stress disorder following childbirth: current issues and recommendations for future research. Journal of Psychosomatic Obstetrics \& Gynecology, 29(4), 240-250.

Ayers, S., \& Pickering, A. D. (2001). Do women get posttraumatic stress disorder as a result of childbirth? A prospective study of incidence. Birth (Berkeley, Calif.), 28, 111-118. doi:10.1046/j.1523-536X.2001.00111.x

Badenhorst, W., \& Hughes, P. (2007). Psychological aspects of perinatal loss. Best Practice and Research: Clinical Obstetrics and Gynaecology. doi:10.1016/j.bpobgyn.2006.11.004

Bailham, D., \& Joseph, S. (2003). Post-traumatic stress following childbirth: a review of the emerging literature and directions for research and practice. Psychology, Health \& Medicine, 8(2), 159-168.

Bansen, S. S., \& Stevens, H. A. (1992). Women's experiences of miscarriage in early pregnancy. Journal of Nurse-Midwifery, 37(2), 84-90. 
380

Beck, C. T. (2004). Post-traumatic stress disorder due to childbirth: the aftermath. Nursing Research, 53(4), 216-224.

Beck, C. T. (2011). A metaethnography of traumatic childbirth and its aftermath: Amplifying causal looping. Qualitative Health Research, 21(3), 301-311.

Beck, C. T., \& Driscoll, J. (2006). Postpartum mood and anxiety disorders: A clinician's guide. Jones \& Bartlett Learning.

Beck, C. T., \& Watson, S. (2008). Impact of birth trauma on breast-feeding: a tale of two pathways. Nursing Research, 57(4), 228-236.

Boyle, F. M., Vance, J. C., Najman, J. M., \& Thearle, M. J. (1996). The mental health impact of stillbirth, neonatal death or sids: Prevalence and patterns of distress among mothers. Social Science and Medicine, 43, 1273-1282. doi:10.1016/0277-9536(96)00039-1

Brockington, I. (1996). Motherhood and mental health.

Cacciatore, J., Schnebly, S., \& Froen, J. F. (2009). The effects of social support on maternal anxiety and depression after stillbirth. Health \& Social Care in the Community, 17(2), $167-176$.

Challacombe, F., \& Salkovskis, P. (2009). A preliminary investigation of the impact of maternal obsessive-compulsive disorder and panic disorder on parenting and children. Journal of Anxiety Disorders, 23, 848-857. doi:10.1016/j.janxdis.2009.04.002

Cohen, S., \& Wills, T. A. (1985). Stress, social support, and the buffering hypothesis. Psychological Bulletin, 98(2), 310-357. doi:10.1037/0033-2909.98.2.310 
400 Cornwell, J., \& Goodrich, J. (2009). Exploring how to enable compassionate care in hospital to improve patient experience. Nursing Times, 105(15), 14-21.

402 Côté-Arsenault, D., Bidlack, D., \& Humm, A. (2001). Women's emotions and concerns 403 during pregnancy following perinatal loss. MCN: The American Journal of $404 \quad$ Maternal/Child Nursing, 26(3), 128-134.

405 Cox, J. L., Holden, J. M., \& Sagovsky, R. (1987). Detection of Postnatal Depression: 406 Development of the 10-item Edinburgh Postnatal Depression scale. British Journal of Psychiatry, 150, 782-786. doi:10.1192/bjp.150.6.782

Cumming, G. P., Klein, S., Bolsover, D., Lee, A. J., Alexander, D. A., Maclean, M., \& 409 Jurgens, J. D. (2007). The emotional burden of miscarriage for women and their partners: Trajectories of anxiety and depression over 13 months. BJOG: An International Journal of Obstetrics and Gynaecology, 114, 1138-1145.

Czarnocka, J., \& Slade, P. (2000). Prevalence and predictors of post-traumatic stress symptoms following childbirth. The British Journal of Clinical Psychology / the British doi:10.1111/j.1471-0528.2007.01452.x

Davis, D. L., Stewart, M., \& Harmon, R. J. (1988). Perinatal Loss: Providing Emotional Support for Bereaved Parents. Birth, 15(4), 242-246. doi:10.1111/j.1523536X.1988.tb01118.x

DiBartolo, P. M., \& Helt, M. (2007). Theoretical models of affectionate versus affectionless control in anxious families: A critical examination based on observations of parent-child 
interactions. Clinical Child and Family Psychology Review, 10, 253-274.

422 doi:10.1007/s 10567-007-0017-5

423

424

425

426

427

428

429

430

431

432

433

434

435

436

437

438

439

440

Elmir, R., Schmied, V., Wilkes, L., \& Jackson, D. (2010). Women's perceptions and experiences of a traumatic birth: A meta-ethnography. Journal of Advanced Nursing. doi:10.1111/j.1365-2648.2010.05391.x

Field, T., Healy, B. T., Goldstein, S., \& Guthertz, M. (1990). Behavior-state matching and synchrony in mother-infant interactions of nondepressed versus depressed dyads. Developmental Psychology. doi:10.1037/0012-1649.26.1.7

House, J. S., \& Kahn, R. L. (1985). Measures and concepts of social support. Social support and health. In Social support and health (pp. 83-108). Retrieved from http://psycnet.apa.org/psycinfo/1985-97489-005

Hughes, P. M., Turton, P., \& Evans, C. D. (1999). Stillbirth as risk factor for depression and anxiety in the subsequent pregnancy: cohort study. BMJ (Clinical Research Ed.), 318, 1721-1724. doi:10.1136/bmj.318.7200.1721

Hughes, P., Turton, P., Hopper, E., \& Evans, C. D. (2002). Assessment of guidelines for good practice in psychosocial care of mothers after stillbirth: a cohort study. Lancet, 360, 114-8. doi:S0140673602094102

Iles, J., \& Pote, H. (2015). Postnatal posttraumatic stress: A grounded theory model of firsttime mothers' experiences. Journal of Reproductive and Infant Psychology, (ahead-ofprint), $1-18$.

Kavanaugh, K., Trier, D., \& Korzec, M. (2004). Social support following perinatal loss. Journal of Family Nursing, 10(1), 70-92. doi:10.1177/1074840703260905 
Leon, I. G. (1986). The invisible loss: The impact of perinatal death on siblings. Journal of Psychosomatic Obstetrics \& Gynecology, 5(1), 1-14.

445

446

447

448

449

450

451

452

453

454

455

456

457

458

459

460

461

462

463

Lim, L., Ng, T. P., Chua, H. C., Chiam, P. C., Won, V., Lee, T., ... Kua, E. H. (2005). Generalised anxiety disorder in Singapore: Prevalence, co-morbidity and risk factors in a multi-ethnic population. Social Psychiatry and Psychiatric Epidemiology, 40(12), 972979. doi:10.1007/s00127-005-0978-y

Lok, I. H., Yip, A. S.-K., Lee, D. T.-S., Sahota, D., \& Chung, T. K.-H. (2010). A 1-year longitudinal study of psychological morbidity after miscarriage. Fertility and Sterility, 93, 1966-1975. doi:10.1016/j.fertnstert.2008.12.048

McGuinness, M., Blissett, J., \& Jones, C. (2011). OCD in the perinatal period: is postpartum OCD (ppOCD) a distinct subtype? A review of the literature. Behavioural and Cognitive Psychotherapy, 39(3), 285-310. doi:10.1017/S1352465810000718

McKenzie-McHarg, K., Ayers, S., Ford, E., Horsch, A., Jomeen, J., Sawyer, A., ... Slade, P. (2015). Post-traumatic stress disorder following childbirth: an update of current issues and recommendations for future research. Journal of Reproductive and Infant Psychology, (ahead-of-print), 1-19.

Milgrom, J., Gemmill, A. W., Bilszta, J. L., Hayes, B., Barnett, B., Brooks, J., ... Buist, A. (2008). Antenatal risk factors for postnatal depression: A large prospective study. Journal of Affective Disorders, 108, 147-157. doi:10.1016/j.jad.2007.10.014

Murray, L., Cooper, P., Creswell, C., Schofield, E., \& Sack, C. (2007). The effects of maternal social phobia on mother-infant interactions and infant social responsiveness. 

doi:10.1111/j.1469-7610.2006.01657.x

466

467

468

469

470

Nansel, T. R., Doyle, F., Frederick, M. M., \& Zhang, J. (2005). Quality of life in women undergoing medical treatment for early pregnancy failure. JOGNN: Journal of Obstetric, Gynecologic \& Neonatal Nursing, 34, 473-481. doi:10.1177/0884217505278319

Ney, P. G., Fung, T., Wickett, A. R., \& Beaman-Dodd, C. (1994). The effects of pregnancy loss on women's health. Social Science \& Medicine, 38, 1193-1200.

Rambelli, C., Montagnani, M. S., Oppo, A., Banti, S., Borri, C., Cortopassi, C., ... Mauri, M. (2010). Panic disorder as a risk factor for post-partum depression. Results from the Perinatal Depression-Research \& Screening Unit (PND-ReScU) study. Journal of Affective Disorders, 122(1-2), 139-143. doi:10.1016/j.jad.2009.07.002

Reynolds, J. L. (1997). Post-traumatic stress disorder after childbirth: The phenomenon of traumatic birth. CMAJ.

Rogers, C. R. (1951). Client-centered therapy: Its current practice, implications and theory. Houghton Mifflin Boston.

Soet, J. E., Brack, G. A., \& Dilorio, C. (2003). Prevalence and predictors of women's experience of psychological trauma during childbirth. Birth, 30, 36-46. doi:10.1046/j.1523-536X.2003.00215.X

Ustundag- Budak, A. M., Larkin, M., Harris, G., \& Blissett, J. (2015). Mothers' accounts of their stillbirth experiences and of their subsequent relationships with their living infant: an interpretative phenomenological analysis. BMC Pregnancy and Childbirth, 15(1), 114. doi:10.1186/s12884-015-0700-3 
486 Wijma, K., Söderquist, J., \& Wijma, B. (1997). Posttraumatic stress disorder after childbirth: a cross sectional study. Journal of Anxiety Disorders, 11, 587-97. Retrieved from http://www.ncbi.nlm.nih.gov/pubmed/9455721

Zaers, S., Waschke, M., \& Ehlert, U. (2008). Depressive symptoms and symptoms of posttraumatic stress disorder in women after childbirth. Journal of Psychosomatic Obstetrics and Gynaecology, 29, 61-71. doi:10.1080/01674820701804324

492 Zimmerman, M., \& Mattia, J. I. (2001). A self-report scale to help make psychiatric 493 diagnoses: the Psychiatric Diagnostic Screening Questionnaire. Archives of General $494 \quad$ Psychiatry, 58, 787-794. doi:10.1001/archpsyc.58.8.787 
496 Tables

497 Table 1. Demographic differences in PDSQ scores of single trauma with or without loss

498 groups $(\mathrm{n}=144)$

499

500 Table 2. Univariate analysis of variance for the differences between trauma without loss and

501 trauma with loss scores on the PDSQ and PDSQ sub scores $(n=144)$

502

503 Table 3. Univariate variance analysis for the differences between trauma without loss and

504 trauma with loss scores on the PDSQ and PDSQ sub scores of women with no mental health

505 history $(\mathrm{n}=107)$

506

507 Table 4. Univariate analysis of variance for the differences between trauma without loss and

508 trauma with loss scores on perceived emotional support $(\mathrm{n}=142)$

\section{$509 \quad$ Figures}

510 Figure1. PDSQ total and sub scale scores by trauma group

511 
512 Table1. Demographic differences in PDSQ scores of single trauma with or without loss

513 groups $(n=144)$

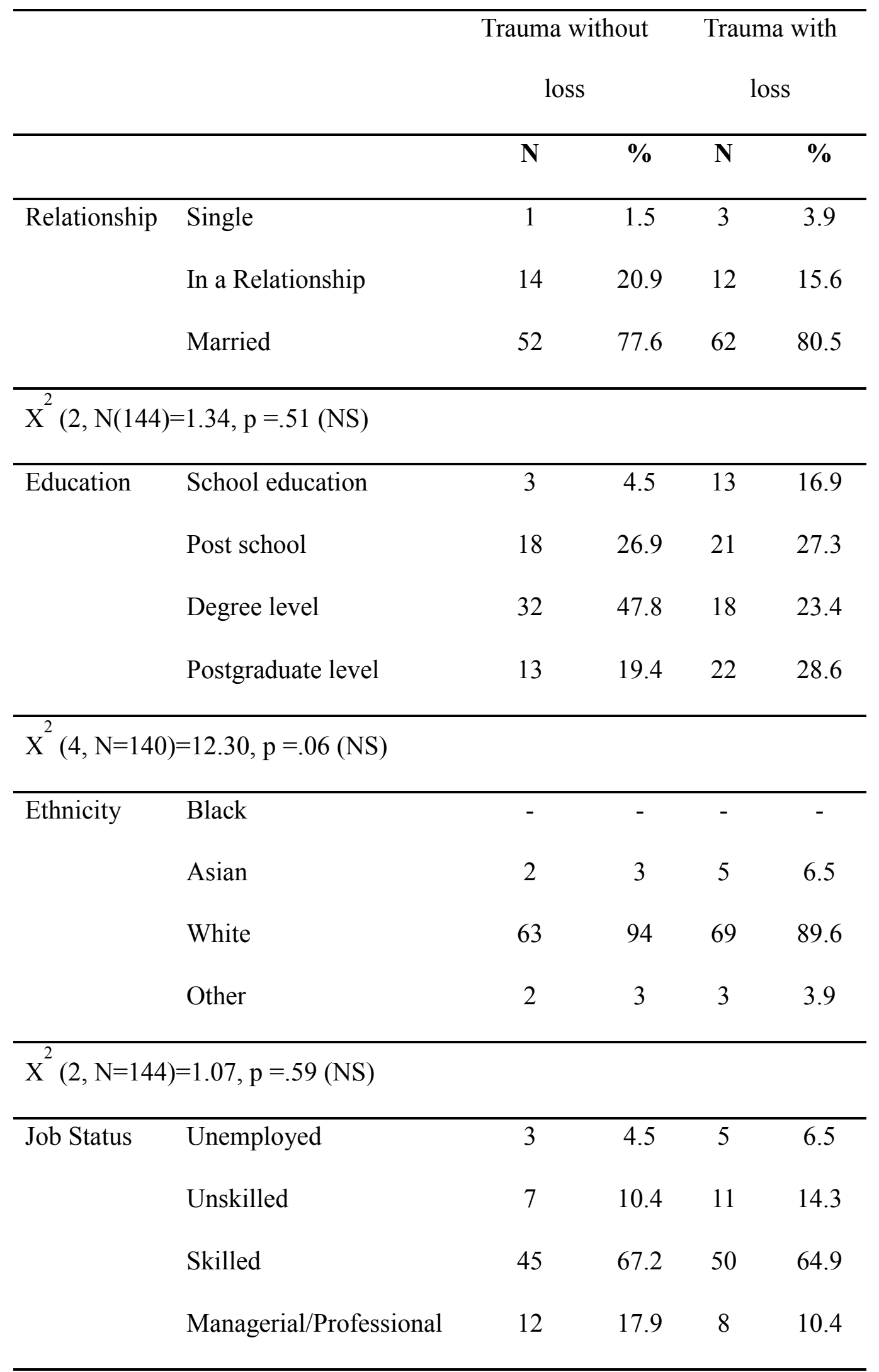




$$
X^{2}(5, N=141)=3.68, p=.60(N S)
$$

\section{Previous}

Mental Health Yes

$\begin{array}{llll}24 & 35.8 & 13 & 16.9\end{array}$

Problem

No

$\begin{array}{llll}43 & 64.2 & 64 & 83.1\end{array}$

$\mathrm{X}^{2}(2, \mathrm{~N}=144)=5.77, \mathrm{p}=.02(\mathrm{~S})$

514

515 
516 Table 2. Univariate analysis of variance for the differences between trauma without loss and

517 trauma with loss scores on the PDSQ and PDSQ sub scores $(n=144)$

\begin{tabular}{|c|c|c|c|c|c|c|c|c|c|}
\hline & \multicolumn{3}{|c|}{ Trauma without } & \multicolumn{3}{|c|}{ Trauma with } & & & \\
\hline & & Loss & & & Loss & & & & \\
\hline & $\mathrm{M}$ & SD & $\mathrm{N}$ & $\mathrm{M}$ & SD & $\mathrm{N}$ & $\mathrm{F}$ & Df & $\mathrm{p}$ \\
\hline PDSQ Total & 29.74 & 17.49 & 61 & 23.14 & 15.20 & 58 & 4.81 & $1-117$ & $.03^{*}$ \\
\hline $\begin{array}{l}\text { Obsessive Compulsive } \\
\text { Disorder (OCD) }\end{array}$ & 1.02 & 1.52 & 66 & 0.47 & 0.94 & 73 & 6.66 & $1-137$ & $.01^{*}$ \\
\hline Panic Disorder & 2.45 & 2.72 & 65 & 1.35 & 2.05 & 71 & 7.07 & $1-134$ & $.01^{*}$ \\
\hline PTSD & 7.23 & 4.23 & 62 & 4.65 & 4.11 & 63 & 11.93 & $1-123$ & $.03^{*}$ \\
\hline Major Depression & 6.75 & 5.14 & 61 & 6.32 & 4.42 & 62 & .25 & $1-121$ & .62 \\
\hline Agoraphobia & 1.82 & 2.60 & 62 & 1.33 & 2.02 & 63 & 1.38 & $1-123$ & .24 \\
\hline Social Phobia & 4.47 & 4.13 & 62 & 3.63 & 4.29 & 59 & 1.21 & $1-119$ & .27 \\
\hline $\begin{array}{l}\text { Generalised Anxiety } \\
\text { Disorder (GAD) }\end{array}$ & 5.61 & 3.46 & 62 & 4.34 & 3.44 & 61 & 4.16 & $1-121$ & $.03^{*}$ \\
\hline $\begin{array}{l}\text { Depression measured } \\
\text { by EPDS }\end{array}$ & 14.40 & 6.99 & 56 & 12.90 & 5.57 & 52 & 1.53 & $1-106$ & .22 \\
\hline
\end{tabular}

518

$* \mathrm{p}<0.5$

519

520

521

522

523 
524 Table 3. Univariate variance analysis for the differences between trauma without loss and 525 trauma with loss scores on the PDSQ and PDSQ sub scores of women with no mental health 526 history $(n=107)$

\begin{tabular}{|c|c|c|c|c|c|c|c|c|c|}
\hline \multicolumn{4}{|c|}{ Trauma without Loss } & \multicolumn{6}{|c|}{ Trauma with Loss } \\
\hline & $\mathrm{M}$ & SD & $\mathrm{N}$ & $\mathrm{M}$ & SD & $\mathrm{N}$ & $\mathrm{F}$ & $\mathrm{df}$ & $\mathrm{p}$ \\
\hline PDSQ Total & 23.74 & 15.05 & 38 & 22.09 & 14.40 & 46 & 0.26 & 182 & 0.61 \\
\hline OCD & 0.69 & 1.30 & 42 & 0.48 & 0.97 & 60 & 0.86 & 1100 & 0.36 \\
\hline Panic & 1.69 & 2.41 & 42 & 1.26 & 1.90 & 58 & 1.00 & 198 & 0.32 \\
\hline PTSD & 6.38 & 4.14 & 39 & 4.31 & 3.94 & 51 & 5.84 & 188 & $.018^{*}$ \\
\hline $\begin{array}{l}\text { Major } \\
\text { Depression }\end{array}$ & 5.26 & 4.55 & 38 & 5.86 & 4.31 & 50 & 0.39 & 186 & 0.53 \\
\hline Agoraphobia & 1.05 & 1.85 & 39 & 1.28 & 1.95 & 50 & 0.32 & 187 & 0.58 \\
\hline Social & 3.62 & 4.13 & 39 & 3.67 & 4.34 & 46 & 0.00 & 183 & 0.95 \\
\hline GAD & 4.46 & 3.36 & 39 & 4.23 & 3.32 & 48 & 0.10 & 185 & 0.75 \\
\hline EPDS & 12.12 & 6.63 & 35 & 12.43 & 5.36 & 40 & 0.50 & 173 & .821 \\
\hline
\end{tabular}

527

528

529

530 
Table 4. Univariate analysis of variance for the differences between trauma without loss and trauma with loss scores on perceived emotional support $(n=142)$

\section{Trauma without Loss $\quad$ Trauma with Loss}

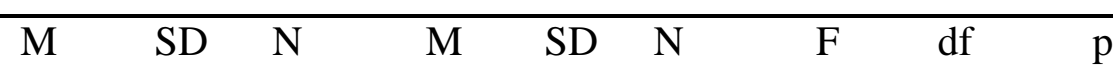

Perceived

Emotional

$\begin{array}{lllllllllll}\text { Support from } & 1.92 & 1,03 & 66 & 2.67 & 1.20 & 76 & 15.55 & & 0.0001 *\end{array}$

Health

Practitioner

Perceived

Emotional

Support from

$\begin{array}{lllllllll}3.27 & 1.44 & 66 & 3.91 & 1.25 & 76 & 7.94 & 1 & 0.01 *\end{array}$

Partner

Perceived

Emotional

Support from

$\begin{array}{lllllllll}2.93 & 1.33 & 61 & 3.00 & 1.24 & 74 & .088 & & 0.77\end{array}$

Family

$* p<.05$ 


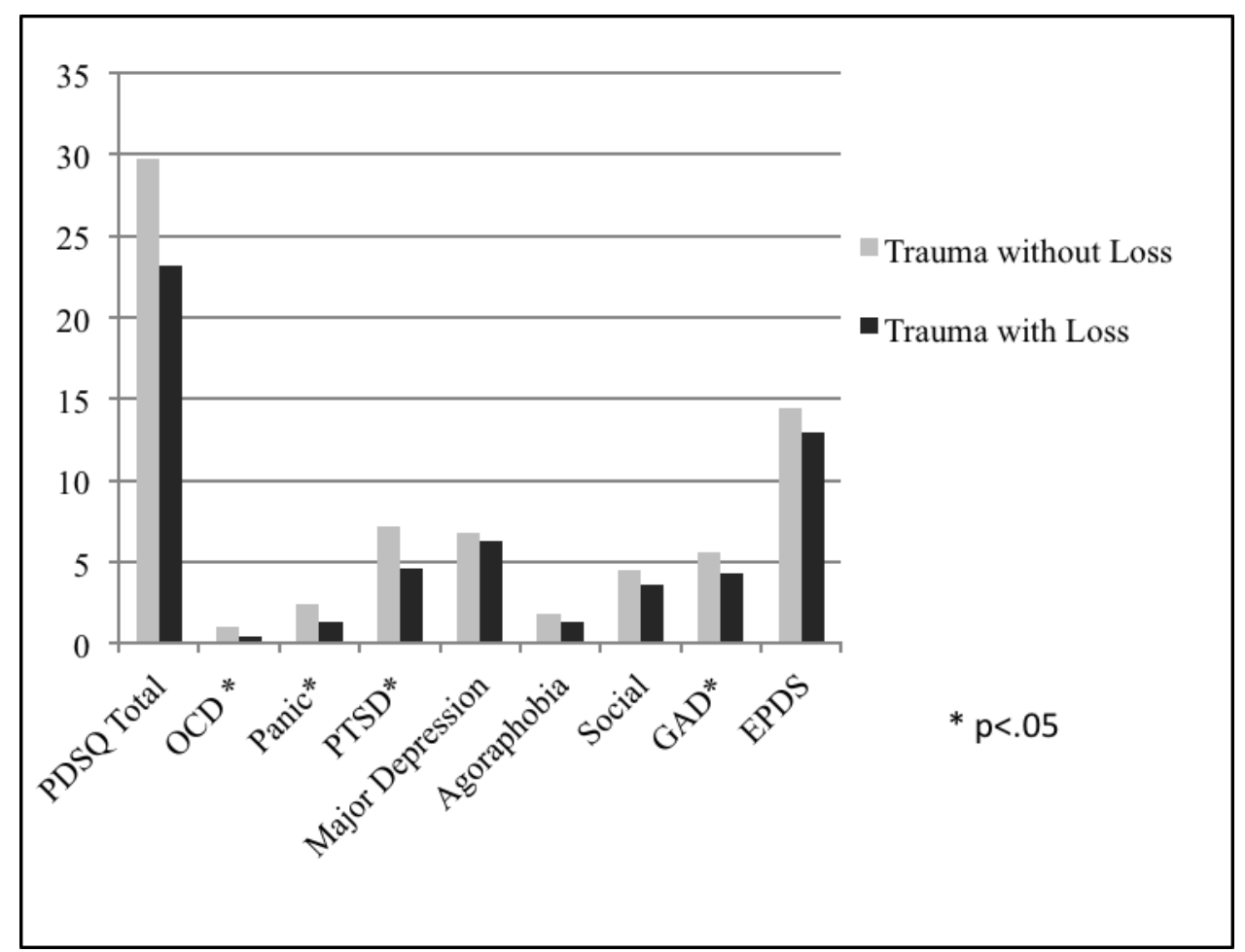

Figure 1. PDSQ total and sub scale scores by trauma group 